\title{
Preliminary validation of the refractivity from the new radio occultation sounder GNOS/FY-3C
}

\author{
Mi Liao ${ }^{1,2,3}$, Peng Zhang ${ }^{3}$, Guang-Lin Yang ${ }^{3}$, Yan-Meng Bi ${ }^{3}$, Yan Liu ${ }^{2}$, Wei-Hua Bai ${ }^{4}$, Xiang-Guang Meng ${ }^{4}$, \\ Qi-Fei $\mathrm{Du}^{4}$, and Yue-Qiang $\mathrm{Sun}^{4}$ \\ ${ }^{1}$ Nanjing University of Information Science \& Technology, Nanjing, China \\ ${ }^{2}$ Chinese Academy of Meteorological Sciences, Beijing, China \\ ${ }^{3}$ National Satellite Meteorological Center, Beijing, China \\ ${ }^{4}$ Center for Space Science and Applied Research, Beijing, China \\ Correspondence to: Peng Zhang (zhangp@cma.gov.cn)
}

Received: 5 May 2015 - Published in Atmos. Meas. Tech. Discuss.: 1 September 2015

Revised: 3 February 2016 - Accepted: 9 February 2016 - Published: 2 March 2016

\begin{abstract}
As a new member of the space-based radio occultation sounders, the GNOS (Global Navigation Satellite System Occultation Sounder) mounted on Fengyun3C (FY-3C) has been carrying out atmospheric sounding since 23 September 2013. GNOS takes approximately 800 daily measurements using GPS (Global Positioning System) and Chinese BDS (BeiDou navigation satellite) signals. In this work, the atmospheric refractivity profiles from GNOS were compared with the ones obtained from the co-located ECMWF (European Centre for Medium-Range Weather Forecasts) reanalysis. The mean bias of the refractivity obtained through GNOS GPS (BDS) was found to be approximately $-0.09 \%(-0.04 \%)$ from the near surface to up to $46 \mathrm{~km}$. While the average standard deviation was approximately $1.81 \%(1.26 \%)$, it was as low as $0.75 \%$ $(0.53 \%)$ in the range of $5-25 \mathrm{~km}$, where best sounding results are usually achieved. Further, COSMIC (Constellation Observing System for Meteorology, Ionosphere and Climate) and MetOp/ GRAS (GNSS Receiver for Atmospheric Sounding) radio occultation data were compared with the ECMWF reanalysis; the results thus obtained could be used as reference data for GNOS. Our results showed that GNOS/FY-3C meets the design requirements in terms of accuracy and precision of the sounder. It possesses a sounding capability similar to COSMIC and MetOp/GRAS in the vertical range of 0-30 km, though it needs further improvement above $30 \mathrm{~km}$. Overall, it provides a new data source for the global numerical weather prediction (NWP) community.
\end{abstract}

\section{Introduction}

When a ray transmitted by the Global Navigation Satellite System (GNSS) passes through the atmosphere, the signal received by the GNSS receiver on a low Earth orbit (LEO) satellite is bent and delayed. The GNSS receiver records the bending and delay information in terms of amplitude and phase, which is related to the physical conditions of the atmosphere (Kursinski et al., 1996). Atmosphere sounding using the radio occultation (RO) technique was proposed by Fishbach (1965) and Lusignan et al. (1969) and the first practical application of this technique was in the GPS/Met (Global Positioning System/Meteorology) experiment (Ware et al., 1996; Kursinski et al., 1996, 1997; Rocken et al., 1997). With the advantages of high vertical resolution, high accuracy, all-weather sounding, self-calibration, long-term stability, global coverage, and low cost, RO-based operations were regularly carried out, some of which include the German CHAMP (CHAllenging Minisatellite Payload; Wickert et al., 2001), the Argentinian SAC-C (Satellite de Aplicaciones Cientificas-C; Hajj et al., 2004), the US/German GRACE (Gravity Recovery and Climate Experiment) (Beyerle et al., 2005), the Taiwanese/US COSMIC (Constellation Observing System for Meteorology, Ionosphere, and Climate; Anthes et al., 2008), and the European MetOp/GRAS (GNSS Receiver for Atmospheric Sounding) mission (Von Engeln et al., 2009). The data from these missions are widely used in the field of numerical weather prediction (NWP) (Healy and Thepaut, 2006; Aparicio and Deblonde, 2008; Cucurull and Derber, 2008; Rennie, 2010) and climate change (Anthes et 
al., 2000; Anthes, 2011; Steiner et al., 2011). The RO profiles are used for space weather monitoring as well (Yue et al., 2010). Considering the high profitability of the RO data, China has been developing space-based RO technology since the 2000s (Yang et al., 2012). The first satellite-based RO instrument named GNOS (Global Navigation Satellite System Occultation Sounder) was launched on 23 September 2013 and mounted on the Chinese polar orbiting meteorological satellite Fengyun-3C (FY-3C) (Bai et al., 2014).

A lot of work has been done to demonstrate the accuracy of the RO data obtained from several missions (Kursinski et al., 1996; Rocken et al., 1997; Hajj et al., 2002, 2004; Poli et al., 2003; Schreiner et al., 2011). Kuo et al. (2005) pointed out that the RO data at altitudes of 5-25 km show the highest accuracy; they are able to statistically differentiate various types of radiosondes. In addition, owing to its high accuracy and long-term stability, the RO data can be used as a reference to assess the performances of the current radiosondes (He et al., 2009; Ladstädter et al., 2015). Schreiner et al. (2007) evaluated the precision of the refractivity data from the COSMIC/FORMOSAT-3 mission. His work showed that the root-mean-square difference is less than $0.2 \%$ within an altitude range of $10-20 \mathrm{~km}$. Using the pre-launch proxy data, Bi et al. (2012) investigated the possible accuracy of the refractivity profiles from GNOS. The results from their simulations showed the refractivity profiles from the GNOS occultation to be highly accurate in the troposphere and lower stratosphere. A mountain-based experiment was also carried out to validate the performance of GNOS before launch. The experiment also showed that the refractivity profiles obtained by GNOS to be consistent with those from the radiosondes (Bai et al., 2014).

As a brand new member of the space-based RO sounder family, the post-launch performance of GNOS is critical to the user community. Therefore, this study focuses on the validation of the neutral refractivity data from the GNOS measurements. GNOS is a multi-GNSS receiver that can carry out RO measurements from both GPS and Chinese BDS signals. While both the GPS and Chinese BDS have been selected as the operational systems for RO-based measurements, the GNOS BDS products are still currently under evaluation and are not being used in the operational stream. However, for the purpose of comparison, both GNOS-GPS and GNOS-BDS refractivity profiles are validated with the co-located ECMWF reanalysis in this work. The rest of the paper is structured as follows: Sect. 2 briefly describes the processes of GNOS; Sect. 3 introduces the data and method used for the comparative analysis; Sect. 4 presents the results of validation; and finally Sect. 5 summarises the findings of this study.

\section{Overview of GNOS data}

Fengyun 3 (FY-3) is a second-generation polar orbiting satellite in the Chinese meteorological series. The first two satellites of the FY-3 series, i.e., FY-3A and FY-3B, are considered as research and development missions. Therefore, FY-3C is practically the first operational satellite from the FY-3 series (Yang et al., 2012). GNOS is the first RO instrument on-board the Chinese FY-3C meteorological satellite, operated by the National Satellite Meteorological Center (NSMC) of the China Meteorological Administration (CMA). According to the Chinese Fengyun satellite programme, GNOS will be mounted on FY-3D and the satellites following it. GNOS in the FY-3 series is expected to provide RO measurements continuously at least until 2030.

As a multi-GNSS receiver, GNOS has the ability of tracking up to eight GPS satellites and four BDS satellites for precise orbit determination (POD). In addition, it has velocity and anti-velocity antennas for simultaneously tracking at most six and four occultations from GPS and BDS, respectively. Because of the presence of two antennas in opposite directions, both the rising and setting occultations can be retrieved. Further information on the GNOS instrument specifications can be obtained from Bai et al. (2014).

\subsection{Data processing}

This section briefly describes the operational procedure for obtaining GNOS RO products for the ground segment. The procedure mainly involves five steps, from obtaining raw GNOS data to retrieving atmospheric parameters.

\subsubsection{Data preparation}

The raw observations from GNOS consist of phase and SNR (signal to noise ratio) measurements. In addition, auxiliary information provided by the IGS (International GNSS Service), such as the GPS/BDS precise orbits, clock files, Earth orientation parameters, and the coordinates and measurements of the ground stations, are also needed. The IGS ultra rapid orbit products with an approximate accuracy of $10 \mathrm{~cm}$ in orbit are chosen for near-real-time operational use.

\subsubsection{Precise orbit determination}

Highly accurate measurements by the GNSS and LEO satellites in terms of time and position are the key to the successful retrieval of an occultation event. Based on the measurements of pseudo range and carrier phase as well as the attitude information of the GNOS POD antenna, the GNSS clock offsets, precise orbit information, and Earth orientation parameters, LEO POD can be conducted by integrating the equations of celestial motion (Beutler, 2005) using the Bernese software v5.0 (Dach et al., 2007). Finally, precise orbit products with an orbit accuracy of up to $20 \mathrm{~cm}$ can be produced in near-real time. 


\subsubsection{Excess phase calculation}

In the processing of GNOS data, the single difference technique is applied to obtain the excess phase as a function of time in an Earth-centred inertial reference frame. When GNOS receives signals from an occulting GNSS satellite, it also receives signals from a reference GNSS satellite at the same time. With such a reference observation mode, clock errors from the receiver can be removed (Schreiner et al., 2010). It should be noted that while BDS also uses the single difference technique currently, it produces fewer occultation events than GPS on a daily basis because of fewer reference satellites. In theory, under the condition of fewer reference satellites, a zero difference technique should be more appropriate for BDS since it does not require a reference satellite for simultaneous observations but requires an ultra-stable oscillator on an LEO receiver (Beyerle et al., 2005).

\subsubsection{Atmospheric parameter retrieval}

The Radio Occultation Processing Package (ROPP) software (V6.0) developed at ROM SAF (Radio Occultation Meteorology Satellite Application Facility) is used to determine different kinds of atmospheric parameters (Offiler, 2008).

Under the assumption of local spherical symmetry, the bending angles are defined as the transmitted and received ray angles. As a function of impact parameters, the bending angles are determined from the Doppler frequency shift, spacecraft position, and spacecraft velocity measurements (Kursinski et al., 1997). The geometric optics (GO) approximation is assumed with a sufficient accuracy above $25 \mathrm{~km}$, where single-path rays propagate through the atmosphere. The GO retrieval of bending angle uses the standard geometric relationship of GNSS and LEO. However, in the lower and middle troposphere, there are obvious and complicated multipath effects (Sokolovskiy et al., 2003). Therefore, wave optics (also referred to as the canonical transform (CT2) algorithm) retrievals developed by Gorbunov and Lauritsen (2004) are applied below an altitude of $25 \mathrm{~km}$ (Gorbunov et al., 2011).

In order to obtain neutral atmospheric parameters, the ionospheric contribution must be removed. The first step in the process is the deviation of ionosphere-free bending angle. In the L band, the refractivity of the ionosphere is proportional to the inverse square of the frequency, whereas the refractivity of neutral atmosphere is largely independent of frequencies. Thus, a simple dual-frequency linear combination can mostly correct for the first-order ionospheric contribution (Vorob'ev and Krasil'nikova, 1994). This can be done using two frequencies $\left(f_{1}, f_{2}\right)$ and the corresponding bending angles $\left(\alpha_{1}, \alpha_{2}\right)$, as a function of impact parameter $(a)$ (Eq. 1).

$\alpha(a)=\frac{f_{1}^{2} \alpha_{1}(a)-f_{2}^{2} \alpha_{2}(a)}{f_{1}^{2}-f_{2}^{2}}$

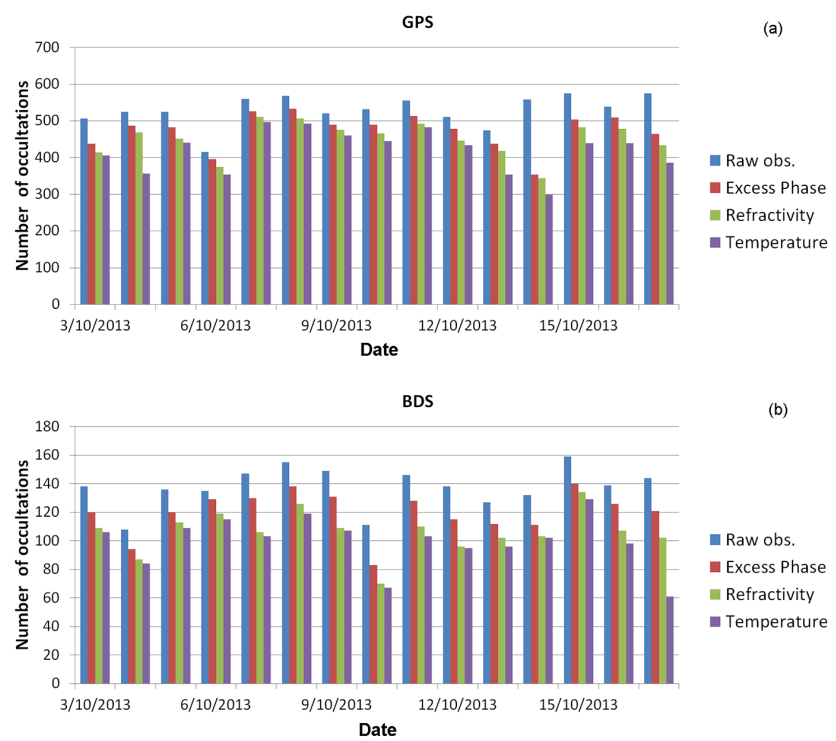

Figure 1. Daily number of occultations for (a) GNOS GPS and (b) GNOS BDS from raw observations to temperature. This is the status of 15 days starting 3 October 2013. Different colours indicate different stages after the corresponding quality control.

However, some ionospheric noise still remains (Kursinski et al., 1997). Therefore, to reduce the ionospheric residual noises, the statistical optimisation technique devised by Gorbunov (2002) is used together with the MSISE-90 climatology model (Hedin, 1991). The optimal linear combination is expressed as a matrix equation to compute the neutral atmospheric bending angle and the ionospheric bending angle.

After ionospheric correction, under the same assumption of local spherical symmetry, the refractive index $n(r)$ and the bending angle are linked with an integral formulation. Abel inversion is applied to derive the refractive index $n(r)$ for a given corrected bending angle $\alpha(a)$, as shown in Eq. (2) (Fjeldbo et al., 1971; Melbourne et al., 1994; Kursinski et al., 1997), and then, refractivity $\mathrm{N}$ can be obtained from the refractive index $n$ (Eq. 3).

$n(r)=\exp \left[\frac{1}{\pi} \int_{x}^{\infty} \frac{\alpha(a)}{\sqrt{a^{2}-x^{2}}} \mathrm{~d} a\right]$,

$N=(n-1) \times 10^{6}$.

Because of the ambiguity regarding dryness and moisture content in the lower troposphere, temperature and humidity profiles cannot be interpreted simultaneously from refractivity (Poli et al., 2002). Therefore, one-dimensional variational (1-D-Var) analysis, combined with the outputs of the T639L60 global forecast model, is used to retrieve temperature and humidity profiles. T639L60 is a global mediumrange weather forecast system of China, which became operational at CMA in 2009. 


\subsubsection{Quality control}

From obtaining raw data to the retrieval of atmospheric parameters, several simple quality controls are applied at each stage through the process. If the occultation time is less than $30 \mathrm{~s}$ or the SNR smaller than 40, the occultation profile will be rejected; if the lowest tangent height of L2 frequency does not reach below $20 \mathrm{~km}$, the occultation profile will be flagged; data are cut off where the estimated bending angle exceeds $0.06 \mathrm{rad}$ at an impact height above $-2 \mathrm{~km}$ and where the straight-line tangent height is above $-250 \mathrm{~km}$; at the temperature retrieval stage, if the absolute temperature difference from the analysis is greater than $10 \mathrm{~K}$, the profile is not produced.

Figure $1 \mathrm{a}$ and $\mathrm{b}$ show the daily number of occultations from raw data measurements to temperature profiles after passing through the correspondent stages of quality control for GNOS GPS and GNOS BDS. From the stage of raw data observations to the calculation of excess phase, $\sim 10 \%(\sim 13 \%)$ GNOS GPS (BDS) observations are excluded. After the second stage of quality control, another $\sim 5 \%(\sim 11 \%)$ GNOS GPS (BDS) observations are excluded. Approximately $7 \%(\sim 6 \%)$ GNOS GPS (BDS) are rejected during the process of refractivity to temperature retrieval.

\subsection{Differences between GNOS GPS RO and BDS RO}

Using the process mentioned above, GNOS GPS and GNOS BDS products are generated in a similar manner. Nevertheless, some slight differences exist since open-loop tracking has not yet been implemented for BDS B1 signals. Thus, processing of open-loop tracking data is not required for B1 signals at present. However, GPS L1 operates based on openloop tracking at sampling rates of $100 \mathrm{~Hz}$ below $10 \mathrm{~km}$ (Bai et al., 2014). The other difference is that the frequencies of B1 and B2 are both modulated by quadrature phase-shift keying (China Satellite Navigation Office, 2013), unlike GPS $\mathrm{L} 2$, which is modulated by a pseudo-random precision ranging code (P code) for anti-spoofing purposes (Spilker, 1978). GNOS, as a classified receiver of BDS, has knowledge of the encryption code and can recover the full signal. Therefore, with respect to GNOS, demodulation of B2 is simpler than L2. Other than the processing differences between GPS RO and BDS RO, there are differences in the distribution of occultations spots as well; these are caused by different orbit implementations of BDS.

The regional Beidou constellation is deployed at three different orbit heights. Including the four recently launched satellites in 2015, 18 satellites have so far been made operational, including six MEO (medium Earth orbit, $21528 \mathrm{~km}$ ), seven IGSO (inclined geosynchronous stationary Earth orbit, $35786 \mathrm{~km}$ ) and five GEO (geosynchronous orbit, $35786 \mathrm{~km}$ ) satellites. In view of the inclinations and sub-satellite tracks, the BDS MEO satellites are similar to those of GPS. The

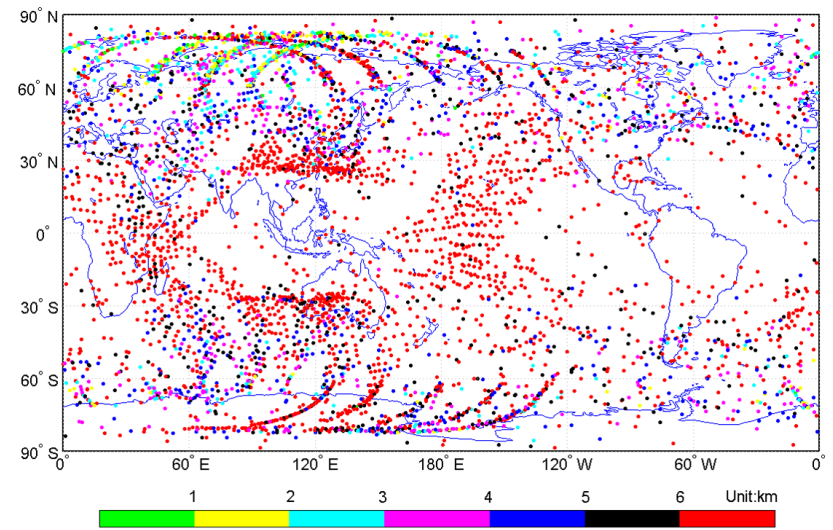

Figure 2. Map of the GNOS BDS occultation coverage from 1 November to 31 December 2013, with a total of 4648 samples. Different colours indicate different penetration depths.

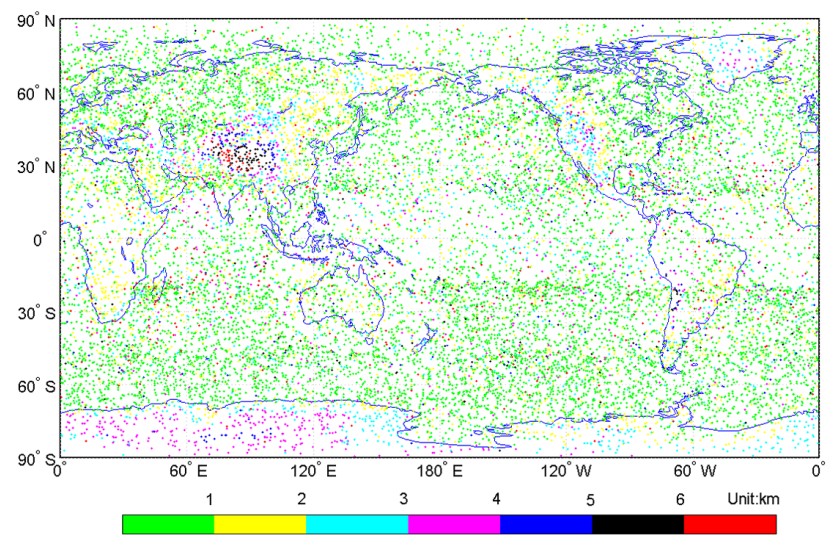

Figure 3. Same as Fig. 2, but for GNOS GPS, with about 17509 profiles.

GEOs are situated over the equator and the sub-satellite track of IGSOs is in the shape of the number " 8 " over the Asia region (Wang et al., 2013). This design results in a unique distribution of BDS RO. As shown in Fig. 2, two circles with a few occultations are located at $110^{\circ} \mathrm{E}$ and $60^{\circ} \mathrm{W}$ on the equator, while a greater number of observations are concentrated on the northern and southern edges of the circles. These kinds of distributions are caused by the IGSOs. In the polar regions, the observations are distributed as arcs because of the GEOs. The rest of the information comes from the MEOs, which acquire a distribution similar to those of GPS and are evenly spread. Therefore, when BDS RO measurements are conducted under specific geometrical conditions, the observations obtained are uneven, while those from GPS RO distribute mostly evenly (Fig. 3).

In addition to these differences, the penetration depths of BDS RO are also markedly higher than GPS RO, which is attributable to the absence of open-loop implementation for B1 signals. Open-loop tracking is aimed at detecting any sig- 
Table 1. Proportion of different penetration depths for GNOS GPS RO and BDS RO from 1 November to 31 December 2013.

\begin{tabular}{lrr}
\hline Penetration depth & GNOS GPS & GNOS BDS \\
\hline$\leq 1 \mathrm{~km}$ & $62 \%$ & $1.3 \%$ \\
$\leq 2 \mathrm{~km}$ & $79.5 \%$ & $5.8 \%$ \\
$\leq 3 \mathrm{~km}$ & $89 \%$ & $13.4 \%$ \\
$\leq 4 \mathrm{~km}$ & $94 \%$ & $24.6 \%$ \\
$\leq 5 \mathrm{~km}$ & $95.7 \%$ & $37.9 \%$ \\
\hline
\end{tabular}

nificant fluctuations in RO signals, after they pass through the moist lower troposphere, without the use of feedback between the received signal and the phase model. It could reduce errors and loss of lock, which cannot be achieved through a closed-loop method (Sokolovskiy et al., 2001). With open-loop tracking capability, the ability to probe deeper into the lower troposphere has been improved (Ao et al., 2009). As shown in Figs. 2 and 3, and Table 1, 37.9\% of GNOS BDS RO profiles reach below $5 \mathrm{~km}$, and only $5.8 \%$ reach below $2 \mathrm{~km}$. The regions where BDS RO profiles reach below $2 \mathrm{~km}$ are located mainly at high latitudes. In the tropics, the penetration depth reaches even higher, almost above $5 \mathrm{~km}$. On the other hand, GNOS GPS RO with open-loop tracking can reach below $5 \mathrm{~km}$ in the proportions of 95.7, and $79.5 \%$ can penetrate up to $2 \mathrm{~km}$, except for the higher-lying areas such as the Tibetan Plateau, western North AmericaGreenland, and the Antarctic continent.

The National Satellite Meteorological Center (NSMC) is responsible for the operation of FY-3C as well as the GNOS instrument. Product generation by GNOS and the dissemination of data thus obtained are routinely done in the ground segment by NSMC. At present, only GNOS GPS products are open to the public, and are available online at http://fy3.satellite.cma.gov.cn. The GNOS BDS products are still under evaluation and are not yet in the operational stream.

\section{Data and method for validation}

\subsection{Data}

The RO refractivity profiles used in this work were obtained from three types of RO missions. The first is the GNOS, containing GNOS GPS RO and BDS RO profiles, whose RO data needed to be validated. Specifically, GNOS GPS RO refractivity profiles were obtained from the operational stream, while those of GNOS BDS RO were obtained from the experimental system, as the system has not yet become operational.

The second type of data was obtained from the COSMIC mission. COSMIC/Formosa satellite 3 is a constellation made up of six micro-satellites, with each one carrying a $\mathrm{RO}$ receiver located in a low Earth orbit (Anthes et al., 2008). The number of daily profiles ranges from 1500 to 2000 with a global distribution. To compare with GNOS RO data, profiles from receiver no. 1 of COSMIC are selected. The COSMIC data are obtained from CDAAC (COSMIC Data Analysis and Archive Center, NCAR, Boulder, USA). The "atmPrf" data set of COSMIC 2013, a new data set obtained through the reprocessing of COSMIC radio occultation data performed at CDAAC, is used for comparison and referred to as COSMIC (http://cdaac-www.cosmic.ucar.edu/ cdaac/products.html).

The third type of refractivity profile used in this study was obtained through MetOp/GRAS. The latter is a joint RO mission that has been conducted by EUMETSAT (European Organization for the Exploitation of Meteorological Satellites) and ESA (European Space Agency) since 2006 (Schreiner et al., 2011). CDAAC processes the data from MetOp/GRAS using the same processing package as COSMIC. Therefore, MetOp/GRAS RO data can be obtained from the CDAAC stream. The reason for selecting COSMIC and MetOp/GRAS data is that they can be taken as benchmarks for GNOS; they employ RO sounders similar to GNOS, are currently operated in orbits, and have the ability to produce stable and high accuracy data.

The data from the ERA-Interim reanalysis are considered as a reference. ERA-Interim is the latest global atmospheric reanalysis produced by the European Centre for Medium-Range Weather Forecasts (ECMWF) (Dee et al., 2011), hereafter called ECMWF reanalysis. Because obtaining data is inconvenient, a pressure-level grid data set is used, whose spatial resolution is approximately $80 \mathrm{~km}$ (T255 spectral) on 37 standard pressure levels from 1000 to $1 \mathrm{hPa}$ (http://apps.ecmwf.int/datasets/data/interim-full-daily/ levtype $=\mathrm{pl})$. For future work, it would be preferable to use ERA-Interim full vertical resolution products.

The data used here are from the same time ranges; more specifications listed in Table 2 summarise the data period and the number of profiles used for the analysis.

\subsection{Method}

To draw a comparison, RO profiles and ECMWF reanalysis must be collated. First is the spatial match. The ECMWF reanalysis and RO profiles are matched within a $\pm 3 \mathrm{~h}$ time interval. The temperature, water vapour pressure, and pressure profiles of the ECMWF reanalysis with a horizontal resolution of $0.75 \times 0.75$ degree are bilinearly interpolated to the location of RO. Then, using the parameters of temperature $(T)$, water vapour partial pressure $(e)$, and air pressure $(P)$, ECMWF reanalysis profiles are calculated into refractivity $(N)$ using the formula Eq. (4) without the ionospheric effects (Kursinski et al., 1997; Rocken et al., 1997).

$$
N=77.6 \frac{P}{T}+3.73 \times 10^{5} \frac{e}{T^{2}}
$$


Table 2. Specifications of RO data and reanalysis data.

\begin{tabular}{llrll}
\hline Data & Time period & $\begin{array}{r}\text { Collated } \\
\text { profiles }\end{array}$ & Source & Note \\
\hline GNOS-GPS & 1 Nov.-31 Dec. 2013 & 17509 & http://fy3.satellite.cma.gov.cn & Near-real-time \\
GNOS-BDS & 1 Nov.-31 Dec. 2013 & 4648 & GNOS experiments system & - \\
MetOp/GRAS & 1 Nov.-31 Dec. 2013 & 32588 & http://cdaac-www.cosmic.ucar.edu/cdaac/products.html & Post-processing \\
COSMIC & 1 Nov.-31 Dec. 2013 & 22821 & http://cdaac-www.cosmic.ucar.edu/cdaac/products.html & Post-processing \\
$\begin{array}{l}\text { ECMWF } \\
\text { reanalysis }\end{array}$ & 1 Nov.-31 Dec. 2013 & - & http://apps.ecmwf.int/datasets/data/interim-full-daily/levtype=pl & Pressure levels, \\
\end{tabular}

Thirdly, both the forward-modelled refractivity and the observational refractivity use the vertical logarithmic interpolation at the same altitude with $200 \mathrm{~m}$ intervals from 0 to $46 \mathrm{~km}$. Thus, the relative difference of refractivity in terms of percentage $\delta N$ is computed from the profiles that were prepared for demonstrating the relative error between ECMWF reanalysis and RO profiles (Eq. 5).

$\delta N=\frac{\left(N_{\mathrm{GNSS}}-N_{\mathrm{ECMWF}}\right)}{N_{\mathrm{ECMWF}}} \times 100 \%$

In total, there are four pairs of ECMWF reanalysis and RO profiles in terms of refractivity: GNOS GPS to ECMWF reanalysis pairs, GNOS BDS to ECMWF reanalysis pairs, COSMIC to ECMWF reanalysis pairs, and MetOp/GRAS to ECMWF reanalysis pairs.

The ensemble mean difference and the standard deviation of the differences at each altitude for each pair can be obtained. In addition to the quality controls at different stages of processes, extra ones are applied during the statistical processes. A profile is rejected if fractional refractivity greater than 0.1 occurs at more than $20 \%$ levels in the profile. Besides, the outliers on a specific level are then excluded if they exceed the $3 \sigma$ from a statistical point of view. Generally, COSMIC and MetOp/GRAS experience a slightly smaller rate of rejected data as compared with GNOS.

\section{Validation results and discussions}

\subsection{Comparison of GNOS refractivity profiles with ECMWF, MetOp/GRAS, and COSMIC}

\subsubsection{GNOS vs. ECMWF}

Figure 4 shows the result of the statistical comparison between GNOS GPS and ECMWF reanalysis. It shows that the mean refractivity difference in units of the percentage amount is very close to zero, exhibiting good agreement with the ECMWF reanalysis and reconfirming the bias-free characteristic of the GPS radio occultation technique. Below the height of $2 \mathrm{~km}$, the mean relative difference of refractivity demonstrates a slight negative bias of $\sim 1 \%$, which is related to the multipath effect due to atmospheric humidity causing
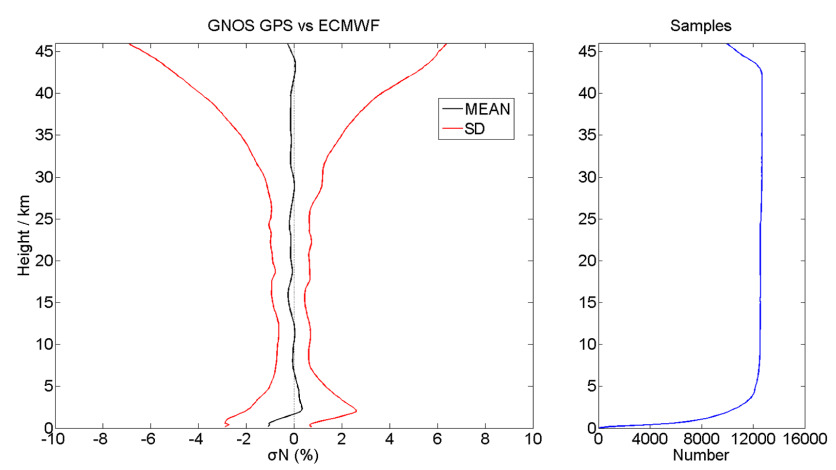

Figure 4. Refractivity deviation from the ECMWF reanalysis for GNOS GPS (from 1 November to 31 December 2013). The left panel shows the mean bias (black) and the standard deviation (red), and the right panel shows the samples used vs. altitude.

strong refractivity gradients (Sokolovskiy et al., 2003, 2009). From 5 to $25 \mathrm{~km}$, little bias is shown, about $-0.09 \%$, reflecting a good performance. As for standard deviation, the highest precision is from 5 to $25 \mathrm{~km}$, smaller than $1 \%$. This is consistent with the results of previous validations for RO data (Kuo et al., 2004; von Engeln et al., 2009; Scherllin-Pirscher et al., 2011). Up to the height of $35 \mathrm{~km}$, the standard deviation is still within $2 \%$, whereas above $35 \mathrm{~km}$, the standard deviation starts to increase with height. This can be attributed to either the reanalysis or the occultation observations. Mainly, as for the occultation, uncalibrated ionospheric effects are a type of error source, and the use of supplementary data for noise reduction through an optimisation procedure also introduces errors (Kuo et al., 2004).

Figure 5 demonstrates the result of GNOS BDS. The mean deviation in the altitude range of $0-46 \mathrm{~km}$ is approximately $-0.04 \%$, which shows less negatively than GNOS GPS. The vertical averaged standard deviation is about $1.26 \%$. In the core region of $5-25 \mathrm{~km}$, the standard deviation tends to be about $0.53 \%$. In the lower troposphere, GNOS BDS exhibits a straight curve in terms of standard deviation, except a sharp shift at the lowest level. Nevertheless, it should be noted that the good performance of BDS below $5 \mathrm{~km}$ may be an illusory phenomenon, and that may have something to do with the sampling issues. As seen in Fig. 2, the distributions of 

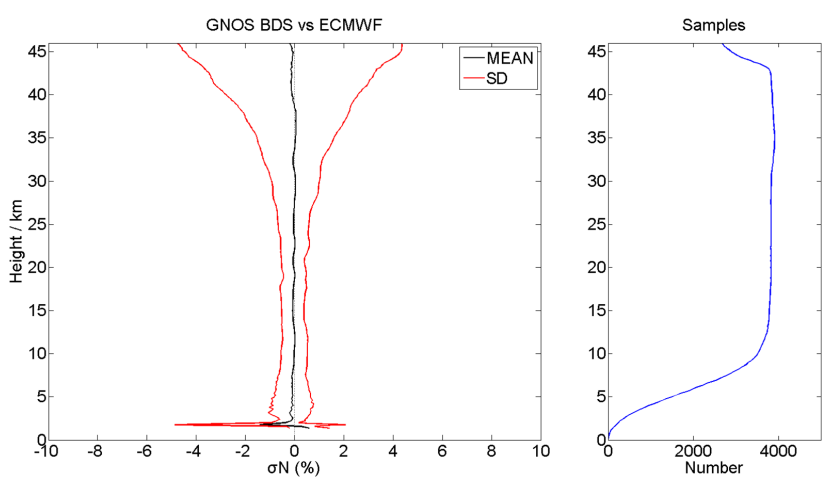

Figure 5. Same as Fig. 4, but for GNOS BDS.
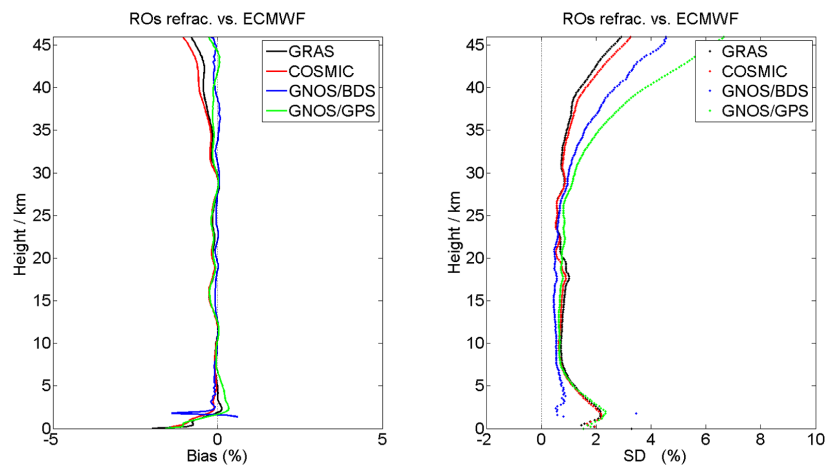

Figure 6. Comparisons of GNOS GPS, GNOS BDS, COSMIC, and MetOp/GRAS with ECMWF reanalysis in terms of refractivity (from 1 November to 31 December 2013). The left panel is the mean bias of different RO data vs. ECMWF reanalysis, and the right panel is the standard deviation for each RO data.

GNOS BDS RO account for few proportions in the tropical lower troposphere, where most difficult conditions are encountered by RO due to a high amount of water vapour, causing a strong gradient. With fewer samples, GNOS BDS distributions mostly show the result of extra tropics and exhibit a smaller standard deviation.

\subsubsection{GNOS, COSMIC, and MetOp/GRAS vs. ECMWF}

In order to better evaluate the performance of GNOS, the COSMIC and MetOp/GRAS RO data, taken as a benchmark to GNOS, are also compared with ECMWF reanalysis. Figure 6 provides the mean and standard deviation of the four types of RO profiles to ECMWF reanalysis. The magnitudes of the corresponding comparison of Fig. 6 are presented in Table 3. Because the reanalysis data are not absolutely perfect either, the bias and standard deviation between RO profiles and ECMWF reanalysis may have come from both of them. However, the errors in the reanalysis are not the main focus of this section. ECMWF reanalysis is used as a platform for the comparison of different RO profiles.
Table 3. Mean bias and standard deviation of refractivity with respect to ECMWF reanalysis for different RO data from 1 November to 31 December 2013.

\begin{tabular}{lrr|rr}
\hline \multirow{2}{*}{ RO data } & \multicolumn{2}{c|}{$0-46 \mathrm{~km}$} & \multicolumn{2}{c}{ 5-25 km } \\
\cline { 2 - 5 } & Mean bias & Mean SD & Mean bias & Mean SD \\
\hline GNOS-GPS & -0.09 & 1.81 & -0.09 & 0.75 \\
GNOS-BDS & -0.04 & 1.26 & -0.04 & 0.53 \\
MetOp/GRAS & -0.19 & 1.11 & -0.11 & 0.79 \\
COSMIC & -0.25 & 1.12 & -0.12 & 0.71 \\
\hline
\end{tabular}

From the near surface to $40 \mathrm{~km}$, the curves of mean bias vs. altitude coincide very well, showing that GNOS including GPS RO and BDS RO is similar to MetOp/GRAS and COSMIC in terms of mean bias. With regard to the standard deviation, the GNOS, COSMIC, and MetOp/GRAS are consistent below $30 \mathrm{~km}$. The magnitudes of GNOS GPS and GNOS BDS are both within $2 \%$ up to $35 \mathrm{~km}$. As reported in prior studies, the RO data spreads from the middle troposphere to the lower stratosphere are most accurate (Kuo et al., 2005). Optimistically, at that vertical range, GNOS shows the highest precision and consistency with respect to the performance of COSMIC and MetOp/GRAS. However, at higher altitudes, we noticed that the standard deviation of GNOS starts to deviate from MetOp/GRAS and COSMIC at about $30 \mathrm{~km}$. Relatively, GNOS BDS shows smaller deviation than GNOS GPS.

Although the source of the difference cannot be completely determined from this result, multiple factors may be assumed to contribute to it. This difference can first be elaborated in terms of different retrieval processes (note that the retrieval processes not only include the ROPP processing, but also the Level 1 processing, which means the processing from the raw data observations to the excess phase). COSMIC and MetOp/GRAS refractivity products are from the CDACC. The data-processing algorithm and initial data set for COSMIC and MetOp/GRAS are in the same baseline, whereas this is not the case for GNOS. For example, in order to save time, we only use 20 ground stations for the calculation of the GPS clock offset, and the POD was computed based on $6 \mathrm{~h}$ data arcs; but COSMIC uses at least 32 stations and is based on $6-12 \mathrm{~h}$ data arcs. Generally, when more stations data are used, the data arcs are computed for longer, and the accuracy of retrievals is higher. This is one important aspect where GNOS data processing should be improved. The other difference is that the data of GNOS are currently obtained from the NRT stream, and the POD is conducted with ultra-rapid IGS orbit products. COSMIC and MetOp/GRAS from CDAAC are post-processed with higher precision. GNOS presents larger standard deviations above $30 \mathrm{~km}$, which are likely caused by the data processing as well, probably indicating that less smoothing is used in GNOS. Besides, data dependency exists. It is known that the COSMIC and MetOp/GRAS RO data have been assimi- 
lated into the ECMWF reanalysis model (Poli et at., 2010). Therefore, GNOS and ECMWF reanalysis are completely independent; if any difference exists, it might be greater than MetOp/GRAS and COSMIC under certain conditions.

Apart from the factors mentioned, residual ionospheric errors may also be dominant above $30 \mathrm{~km}$, which can be inferred from the difference between GNOS GPS and BDS. According to the basic theory, a combination of two frequency measurements forms the basis for separating atmospheric and ionospheric contributions to the bending angle, and in turn the refractivity (Kursinski et al., 1997). As mentioned in Sect. 2, the frequencies of B1 and B2 are modulated using a coarse code, and GNOS, as a classified receiver, has knowledge of the encryption code and can recover the full signal. However, GPS L2 is modulated by a pseudorandom precision ranging code (P code) for the purpose of anti-spoofing. Although GPS L2 can be demodulated using the semi-codeless method, it will be at the expense of SNR and precision, and will probably further lower the efficiency of ionospheric correction when combining the L1 and L2 frequencies (Kursinski et al., 1997). Therefore, it could be said that there are probably some residual errors in the process of GPS L2 frequency signal received by GNOS, resulting in the difference of GNOS GPS and BDS above $30 \mathrm{~km}$.

\subsection{Comparison of GNOS raw bending angle profiles with MetOp/GRAS and COSMIC}

A comparison of the bending angle was conducted to ascertain whether errors also occur at the level of the bending angle, and this part briefly examines the raw bending angles from GNOS GPS after combining L1 and L2 frequencies, but before the process of statistical optimisation. (Note that the reason for not including the data of GNOS BDS is that GNOS GPS and BDS could be expected to show similar features, but it will be interesting to probe the details in future work.)

Firstly, COSMIC and MetOp/GRAS are selected as benchmarks that are directly compared with GNOS GPS without ECMWF reanalysis. Hajj et al. (2004) proposed a close proximity comparison for coincident occultations of CHAMP and SAC-C under the condition that the time is within $1 / 2$ and the distance is $200 \mathrm{~km}$. For more data samples, we limit the time to within $3 \mathrm{~h}$ and the distance less than $200 \mathrm{~km}$. The distance is defined as the distance of tangent heights between two occultations at $30 \mathrm{~km}$ (this means that the distance of some point pairs may be larger than $200 \mathrm{~km}$ ). For the period from 1 November to 31 December 2013, there were 17509 GNOS GPS, 32588 MetOp/GRAS, and 22821 COSMIC occultations to build 1654 GNOS-MetOp/GRAS coincident pairs and 2886 GNOS-COSMIC pairs. It should be noted that although the pairs are restricted to a limited time and space, their comparisons are restricted to different viewing geometries, resulting in different atmospheric and ionospheric propagation.
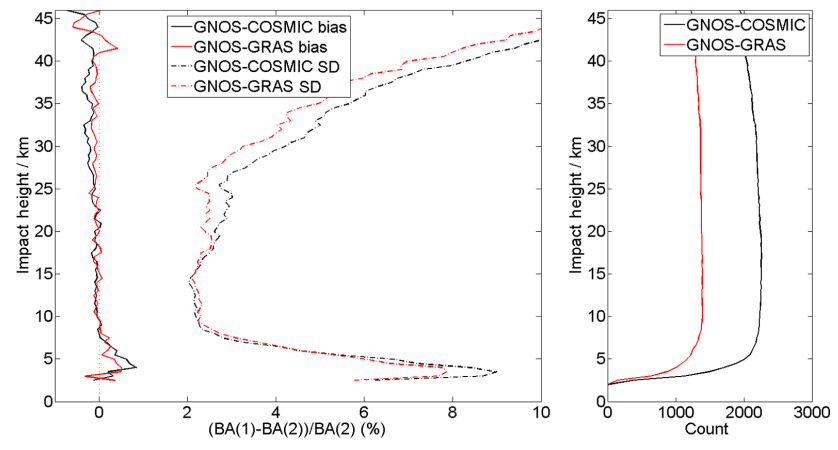

Figure 7. Comparisons of GNOS GPS, COSMIC, and MetOp/GRAS in terms of raw bending angles (from 1 November and 31 December 2013). On the left panel, the solid curves are the mean biases of two pairs, and the dashed curves are the standard deviations. The right panel shows the samples increasing with altitude for the two pairs.

Figure 7 shows the mean and standard deviations of the bending angles in terms of the percentage for the two pairs. The features of standard deviation changing with respect to altitude are similar with the mean bias. The best fit between GNOS, COSMIC, and MetOp/GRAS, in terms of mean bias, occurs at the vertical range of $7-25 \mathrm{~km}$. Some relatively obvious positive and negative deviations exist below $7 \mathrm{~km}$ and above $25 \mathrm{~km}$, respectively, where the SNRs are lower. This kind of comparison of coincident RO profiles does not include the impact of ECMWF reanalysis. Hence, no data dependency contributes to the discrepancy. Apart from the retrieval processing factors mentioned in Sect. 4.1.2, is there any possibility that observational noise from the instrument may also contribute to the deviation?

Figure 8 is the histogram distribution of standard deviation noise of bending angle between 60 and $80 \mathrm{~km}$ heights for GNOS GPS from November to December 2013. The histogram is unimodal with a maximum at $\sim 1 \mu \mathrm{rad}$, and it shows a long "tail" distribution. As the long tail contributes significantly to the mean of standard deviation, the samples with SD greater than $10 \mu \mathrm{rad}$ are removed by considering them as outliers. This results in $\sim 78 \%$ processed samples and a mean SD of $2.29 \mu \mathrm{rad}$. Figure 8 can be compared with Figs. 13 and 14 of Schreiner et al. (2011). If the effects of data periods' discrepancy are neglected, the distribution of SD for GNOS GPS is similar to Fig. 14 of Schreiner et al. (2011), but with a longer tail and a larger mean SD. This may demonstrate some connection with the stability of observations. Above the altitude of $\sim 30 \mathrm{~km}$, the SNR of RO signal gets smaller with an increase in height, and challenges the sounders. Compared with $\pm 55^{\circ}$ of MetOp/GRAS, the occultation antenna gain of GNOS in azimuth is approximately $10 \mathrm{dBi}$ in the range of $\pm 35^{\circ}$ (Bai et al., 2014). This probably results in lower SNRs for GNOS, especially in the weak signal region. Therefore, the observational noise may also partly contribute to the errors of GNOS at higher altitude. 


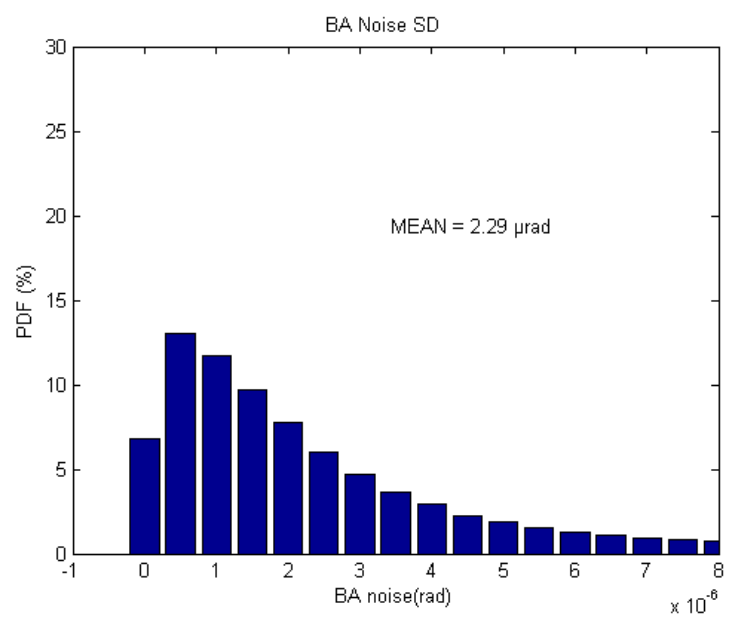

Figure 8. Probability distribution function (PDF) of bending angle (BA) noise in terms of standard deviation for each occultation between 60 and $80 \mathrm{~km}$ heights for $\sim 18000$ GNOS GPS profiles from November to December 2013.

\subsection{Performance in lower troposphere with and without open-loop tracking}

An occultation event occurs when a GNSS satellite rises or sets and the ray path from the GNSS transmitter traverses the Earth's atmosphere (Kursinski et al., 1997). Tracking rising occultation was once a challenge, as it starts from the lower troposphere with a low SNR (Ao et al., 2009). After the openloop tracking was implemented, the tracking ability for rising occultation is much improved (Ao et al., 2009). We know that GNOS uses the technique of open-loop tracking for GPS, but this is not yet implemented for BDS. In this section, the performances of GNOS in the troposphere with and without open-loop tracking are examined.

Figure 9 shows the refractivity deviation of GNOS GPS and GNOS BDS with respect to the ECMWF reanalysis for the rising and setting occultations in the troposphere. From the statistical results of the rising and setting occultations of GNOS GPS, the standard deviation of the rising and setting differs up to $\sim 0.5 \%$. The small positive bias between 2 and $6 \mathrm{~km}$ in the setting occultations is identical to the result of Zus et al. (2011), which used the MetOp/GRAS refractivity and ECMWF reanalysis. As for GNOS BDS, the penetration depths of the rising and setting occultations are both higher than the depths of GNOS GPS, especially in the rising occultation, whose valid height completely stops at $\sim 3 \mathrm{~km}$. Further, the biases of the rising and setting occultations are both larger than the GPS bias below $5 \mathrm{~km}$. These can be mainly attributed to the non-implementation of open-loop tracking for GNOS BDS. This demonstrates that the open-loop tracking technique can strongly improve the ability to track the signal into the lower troposphere (Gorbunov et al., 2011). Clearly, the open-loop tracking for GNOS BDS is essential and will be implemented in the next generations of FY-3.
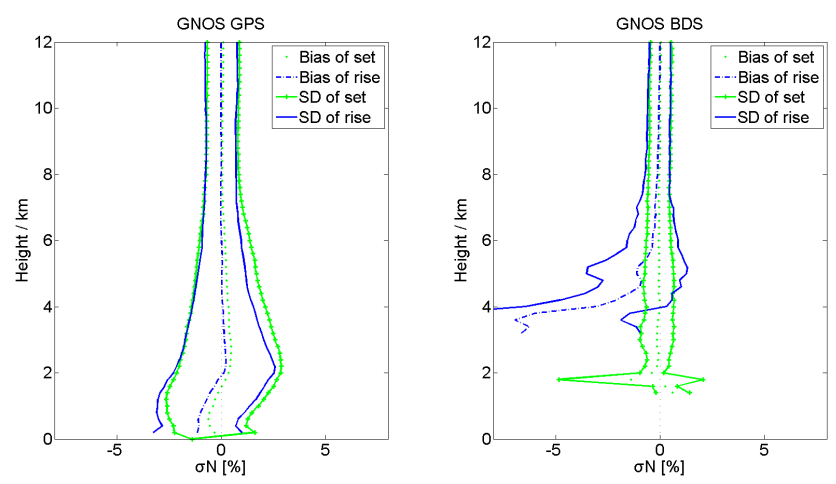

Figure 9. The bias and standard deviation of refractivity of GNOS GPS and BDS with respect to ECMWF reanalysis for the setting and rising occultations (from 1 November to 31 December 2013).

\subsection{Performance in different latitudes}

In this part, GNOS GPS occultations are separated into different latitude bands: the Northern Hemisphere $\left(30-90^{\circ} \mathrm{N}\right)$, the tropics $\left(30^{\circ} \mathrm{N}-30^{\circ} \mathrm{S}\right)$, and the Southern Hemisphere (30$90^{\circ} \mathrm{S}$ ). Based on the orbital characteristics of BDS, shown in Fig. 2, its spatial distributions are not as uniform as GPS RO. Most of the occultations take place around the eastern Hemisphere and leave "holes" at the tropics. Therefore, in order to avoid representativeness errors, we only show the result of GNOS GPS.

Figure 10 shows the statistical results of the mean and standard deviations of refractivity between GNOS GPS and ECMWF reanalysis in different latitude bands. The specific values of mean and standard deviations are shown in Table 4. In the Northern Hemisphere, the curves are more smooth than those in the tropics and in the Southern Hemisphere. In the tropics, more obvious negative and positive biases are found in the lower troposphere, with the largest being $-2 \%$ of bias and $4 \%$ of standard deviation. The error characteristics in this zone are expected to some extent. The conditions in the tropics are more challenging for both NWP models and RO than in the extra tropics. Hence, GNOS GPS and the reanalysis may jointly contribute to their discrepancies. For GNOS GPS, the greater bias and standard deviation in the tropics, especially below $5 \mathrm{~km}$, are related to moist atmosphere, which contributes to the multipath effect (Hajj et al., 2004). Above $\sim 15 \mathrm{~km}$, which is the height of the top troposphere to the low stratosphere, the curves exhibit a fluctuant structure. When compared with ECMWF reanalysis, the curves in both Figs. 10b and 6 show a fluctuant structure in the range of $15-30 \mathrm{~km}$, demonstrating that COSMIC, MetOp/GRAS, and GNOS experienced the same feature (the contribution of the fluctuation in GNOS can be mainly attributed to occultations in the tropical areas). This may be attributed to the lower vertical resolution of ECMWF reanalysis used in this work, which cannot show more details than RO data. Therefore, in the $15-30 \mathrm{~km}$ range, there is a dif- 

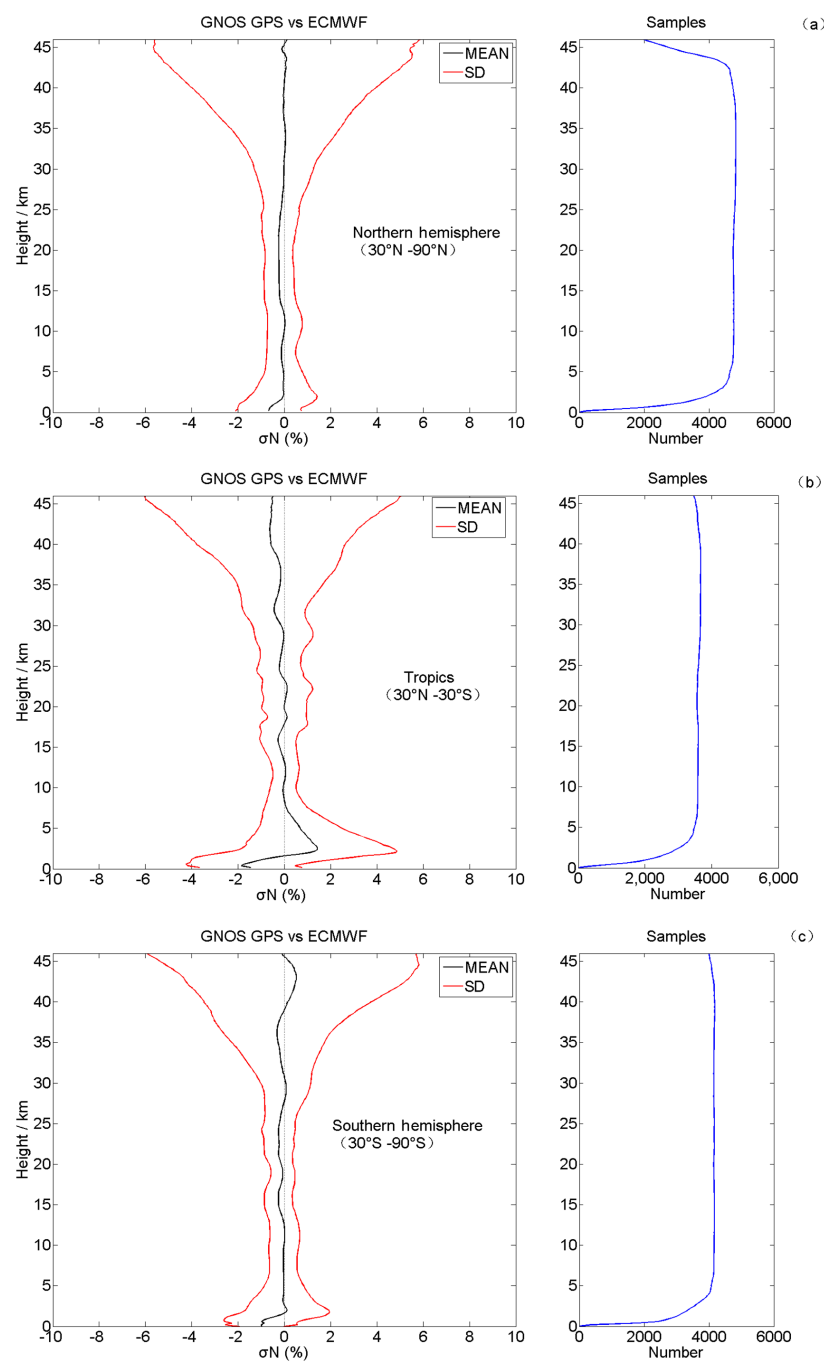

Figure 10. Comparisons of GNOS GPS refractivity with ECMWF reanalysis: (a) for the Northern Hemisphere $\left(30-90^{\circ} \mathrm{N}\right)$, (b) for the tropics $\left(30^{\circ} \mathrm{N}-30^{\circ} \mathrm{S}\right)$, and (c) for the Southern Hemisphere (30$90^{\circ} \mathrm{S}$ ). The left of each panel shows the mean bias (black) and the standard deviation (red), while the right of each panel shows the samples used vs. altitude (from 1 November to 31 December 2013).

ference between the ECMWF reanalysis and RO data. With high vertical resolution, RO data could show more vertical details than ECMWF reanalysis, especially at the height of the tropical cold-point tropopause, and could express the potential for measuring gravity waves (Alexander et al., 2008).

In addition to different latitudes, we evaluated the deviation of GNOS GPS from the ECMWF reanalysis in winter and summer. This is based on the data for the months of December 2013 and August 2014, to examine the different performances in cold and dry conditions as well as in warm and wet conditions. From the result of the former part, the bias of GNOS BDS occultation is more sensitive to moist atmosphere without open-looping tracking. Hence, only GNOS GPS occultation is analysed in terms of seasons.
Table 4. Mean bias and standard deviation (SD) of refractivity with respect to ECMWF reanalysis for GNOS GPS in different latitude bands from 1 November to 31 December 2013.

\begin{tabular}{lrr|rr}
\hline Latitude bands & \multicolumn{2}{c|}{$0-46 \mathrm{~km}$} & \multicolumn{2}{c}{$5-25 \mathrm{~km}$} \\
\cline { 2 - 5 } & Mean bias & Mean SD & Mean bias & Mean SD \\
\hline Northern Hem. & -0.1 & 1.73 & -0.15 & 0.68 \\
Tropics & -0.1 & 1.79 & 0.02 & 0.87 \\
Southern Hem. & -0.07 & 1.61 & -0.12 & 0.62 \\
\hline
\end{tabular}

However, the bias and standard deviations of GNOS GPS for the months of December and August are not substantially different from each other, and therefore, the graph is not shown in this work.

\section{Conclusions and outlook}

The main purpose of this study is to preliminarily evaluate the post-launch performance of GNOS/FY3C. The operational NRT refractivity product of GNOS is compared with the ECMWF reanalysis, as well as the MetOp/GRAS and COSMIC. The results show that the mean bias and standard deviation of refractivity between GNOS GPS (BDS) and ECMWF reanalysis are about $-0.09(-0.04)$ and $1.81 \%$ $(1.26 \%)$, respectively, from the near surface to the altitude of $46 \mathrm{~km}$. The MetOp/GRAS and COSMIC RO data compared with ECMWF reanalysis are also presented for reference. The results demonstrated that GNOS performs similarly to MetOp/GRAS and COSMIC in the $0-30 \mathrm{~km}$ range. As to the different latitude bands, GNOS GPS shows less mean bias and standard deviation in extratropical areas, exhibiting better consistency with ECMWF reanalysis in the Southern and Northern Hemisphere than the tropics, which experience more complicated atmospheric conditions. When separating into the setting and rising occulted modes for GPS and BDS, there is an obvious discrepancy with and without openloop tracking for the rising occultations in the lower troposphere. As a new member of the space-based RO sounder, GNOS/FY-3C can provide the refractivity profile product to the community with satisfactory accuracy below $30 \mathrm{~km}$, with slightly larger standard deviations compared with COSMIC and MetOp/GRAS above $30 \mathrm{~km}$. These deviations are probably dominated jointly by the effect of retrieval errors, such as ionospheric error, and observational errors relating to lower SNR.

More work related to both GNOS GPS and GNOS BDS needs to be conducted to better examine their error characteristics. Using higher vertical resolution products as references would be preferable for future works. There is also a need to quantitatively diagnose the effect of the absence of voluntary signal degradation on B2. Further studies would focus on the performance of GNOS in the middle and upper stratosphere. 
Acknowledgements. The authors are thankful to the CDAAC for providing COSMIC and MetOp/GRAS radio occultation data. We would like to extend our gratitude to ECMWF for providing the reanalysis profiles. We would like to thank ROM SAF for the use of ROPP. We would also like to thank P. Poli (Météo-France) and three anonymous reviewers for their valuable comments and suggestions for future work. Finally, we would like to thank the fund support of the Special Fund for Meteorology Research in the Public Interest (no. 201506074).

Edited by: J. Joiner

\section{References}

Alexander, S. P., Tsuda, T., Kawatani, Y., and Takahashi, M.: Global distribution of atmospheric waves in the equatorial upper troposphere and lower stratosphere: COSMIC observations of wave mean flow interactions, J. Geophys. Res., 113, D24115, doi:10.1029/2008JD010039, 2008.

Anthes, R. A.: Exploring Earth's atmosphere with radio occultation: contributions to weather, climate and space weather, Atmos. Meas. Tech., 4, 1077-1103, doi:10.5194/amt-4-1077-2011, 2011

Anthes, R. A, Rocken, C., and Kuo, Y. H.: Applications of COSMIC to meteorology and climate, Terrestrial Atmospheric and Oceanic Sciences, 11, 115-156, 2000.

Anthes, R. A., Ector, D., Hunt, D. C., Kuo, Y.-H., Rocken, C., Schreiner, W. S., Sokolovskiy, S. V., Syndergaard, S., Wee, T.K., Zeng, Z., Bernhardt, P. A., Dymond, K. F., Chen, Y., Liu, H., Manning, K., Randel, W. J., Trenberth, K. E., Cucurull, L., Healy, S. B., Ho, S.-P., McCormick, C., Meehan, T. K., Thompson, D. C., and Yen, N. L.: The cosmic/formosat-3 mission: Early results, B. Am. Meteorol. Soc., 89, 313-333, 2008.

Ao, C. O., Hajj, G. A., Meehan, T. K., Dong, D., Iijima, B. A., Mannucci, J. A., and Kursinski, E. R.: Rising and setting GPS occultations by use of open-loop tracking, J. Geophys. Res., 114, D04101, doi:10.1029/2008JD010483, 2009.

Aparicio, J. M. and Deblonde, G.: Impact of the Assimilation of CHAMP Refractivity Profiles on Environment Canada Global Forecasts, Mon. Weather Rev., 136, 257-275, 2008.

Bai, W. H., Sun, Y. Q., Du, Q. F., Yang, G. L., Yang, Z. D., Zhang, P., Bi, Y. M., Wang, X. Y., Cheng, C., and Han, Y.: An introduction to the FY3 GNOS instrument and mountain-top tests, Atmos. Meas. Tech., 7, 1817-1823, doi:10.5194/amt-7-1817-2014, 2014.

Beutler, G.: Methods of Celestial Mechanics, Springer-Verlag, Berlin, Heidelberg, New York, Germany, USA, ISBN 3-21182364-6, 2005.

Beyerle, G., Schmidt, T., Michalak, G., Heise, S., Wickert, J., and Reigber, C.: GPS radio occultation with GRACE: Atmospheric profiling utilizing the zero difference technique, Geophys. Res. Lett., 32, L13806, doi:10.1029/2005GL023109, 2005.

Bi, Y.-M., Yang, Z.-D., Zhang, P., Sun, Y.-Q., Bai, W.-H., Du, Q.F., Yang, G. L., Chen, J., and Liao, M.: An introduction to China FY3 radio occultation mission and its measurement simulation, J. Adv. Space Res., 49, 1191-1197, doi:10.1016/j.asr.2012.01.014, 2012.

China Satellite Navigation Office: Beidou navigation satellite system signal in space interface control document-open service sig- nal (Version 2.0), available at: http://en.beidou.gov.cn/ (last access: 9 November 2015), 2013.

Cucurull, L. and Derber, J. C.: Operational implementation of COSMIC observations into NCEP's global data assimilation system, Weather Forecast., 23, 702-711, doi:10.1175/2008WAF2007070.1, 2008.

Dach, R., Hugentobler, U., Fridez, P., and Meindl, M.: Bernese GPS Software Version 5.0. Astronomical Institute, University of Bern, Switzerland, 2007.

Dee, D. P., Uppala, S. M., Simmons, A. J., Berrisford, P., Poli, P., Kobayashi. S., Andrae, U., Balmaseda, M. A., Balsamo, G., Bauer, P., Bechtold, P., Beljaars, A. C. M., van de Berg, L., Bidlot, J., Bormann, N., Delsol, C., Dragani, R., Fuentes, M., Geer, A. J., Haimberger, L., Healy, S. B., Hersbach, H., Hólm, E. V., Isaksen, L., Kållberg, P., Köhler, M., Matricardi, M., McNally, A. P., Monge-Sanz, B. M., Morcrette, J.-J., Park, B.-K., Peubey, C., de Rosnay, P., Tavolato, C., Thépaut, J-N., and Vitart, F.:The ERA-Interim reanalysis: configuration and performance of the data assimilation system, Q. J. Roy. Meteor. Soc., 137, 553-597, doi:10.1002/qj.828, 2011.

Fishbach, F. F.: A satellite method for temperature and pressure below 24 km, B. Am. Meteorol. Soc., 9, 528-532, 1965.

Fjeldbo, G., Kliore, G. A., and Eshleman, V. R.: The neutral atmosphere of Venus as studied with the Mariner V radio occultation experiments, Astron. J., 76, 123-140, 1971.

Gorbunov, M. E.: Ionospheric correction and statistical optimization of radio occultation data, Radio Sci., 37, 17-1-17-9, doi:10.1029/2000RS002370, 2002.

Gorbunov, M. E. and Lauritsen, K. B.: Analysis of wave fields by Fourier Integral Operators and their application for radio occultations, Radio Sci., 39, RS4010, doi:10.1029/2003RS002971, 2004.

Gorbunov, M. E., Lauritsen, K. B., Benzon, H.-H., Larsen, G. B., Syndergaard, S., and Sørensen, M. B.: Processing of GRAS/METOP radio occultation data recorded in closed-loop and raw-sampling modes, Atmos. Meas. Tech., 4, 1021-1026, doi:10.5194/amt-4-1021-2011, 2011.

Hajj, G. A., Kursinski, E. R., Romans, L. J., Bertiger, W. I., and Leroy, S. S.: A technical description of atmospheric sounding by GPS occultation, J. Atmos. Solar-Terr. Phys., 64, 451-469, 2002.

Hajj, G. A., Ao, C. O., Iijima,B. A., Kuang, D., Kursinski,E. R., Mannucci, A. J., Meehan, T. K., Romans, L. J., de la Torre Juarez, M., and Yunck, T. P.: CHAMP and SAC-C atmospheric occultation results and intercomparisons, J. Geophys. Res., 109, D06109, doi:10.1029/2003JD003909, 2004.

He, W., Ho, S. P., Chen, H., Zhou, X., Hunt, D., and Kuo, Y. H.: Assessment of radiosonde temperature measurements in the upper troposphere and lower stratosphere using COSMIC radio occultation data, Geophys. Res. Lett., 36, L17807, doi:10.1029/2009GL038712, 2009.

Healy, S. B. and Thepaut, J. N.: Assimilation experiments with CHAMP GPS radio occultation measurements, Q. J. Roy. Meteorol. Soc., 132, 605-623, doi:10.1256/qj.04.182, 2006.

Hedin, A. E.: Extension of the MSIS thermosphere model into the middle and lower atmosphere, J. Geophys. Res., 96, 1159-1172, 1991.

Kuo, Y.-H., Wee, T.-K., Sokolovskiy, S., Rocken, C., Schreiner, W., Hunt, D., and Anthes, R. A.: Inversion and error estimation of 
GPS radio occultation data, J. Meteor. Soc. Japan, 82, 507-531, 2004.

Kuo, Y.-H., Schreiner, W. S., Wang, J., Rossiter, D. L., and Zhang, Y.: Comparison of GPS radio occultation soundings with radiosondes, Geophys. Res. Lett., 32, L05817, doi:10.1029/2004GL021443, 2005.

Kursinski, E. R., Hajj, G. A., Bertiger, W. I., Leroy, S. S., Meehan, T. K., Romans, L. J., Schofield, J. T., McCleese, D. J., Melbourne, W. G., Thornton, C. L., Yunck, T. P., Eyre, J. R., and Nagatani, R. N.: Initial Results of Radio Occultation Observations of Earth's Atmosphere Using the Global Positioning System, Science, 271, 1107-1110, doi:10.1126/science.271.5252.1107, 1996.

Kursinski, E. R., Hajj, G. A., Hardy, K. R., Schofield, J. T., and Linfield, R.: Observing Earth's atmosphere with radio occultation measurements, J. Geophys. Res., 102, 23429-23465, 1997.

Ladstädter, F., Steiner, A. K., Schwärz, M., and Kirchengast, G.: Climate intercomparison of GPS radio occultation, RS90/92 radiosondes and GRUAN from 2002 to 2013, Atmos. Meas. Tech., 8, 1819-1834, doi:10.5194/amt-8-1819-2015, 2015.

Lusignan, B., Modrell, G., Morrison, A., Pomalaza, J., and Ungar, S. G.: Sensing the Earth's atmosphere with occultation satellites, Proc. IEEE, 4, 458-467, 1969.

Melbourne, W. G., Davis, E. S., Duncan, C. B., Hajj, G. A., Hardy, K. R., Kursinski, E. R., Meehan, T. K., and Young, L. E.: The application of spaceborne GPS to atmospheric limb sounding and global change monitoring, Publication 94-18, Jet Propulsion Laboratory, Pasadena, California, 1994.

Offiler, D.: The radio occultation processing package (ROPP) an overview, Tech. rep., GRAS SAF, Document-No: SAF/GRAS/METO/UG/ROPP/001, 2008.

Poli, P., Joiner, J., and Kursinski, E. R.: 1DVAR analysis of temperature and humidity using GPS radio occultation refractivity data, J. Geophys. Res., 107, 4448, doi:10.1029/2001JD000935, 2002.

Poli, P., Ao, C. O., de la Torre Juárez, M., Joiner, J., Hajj, G. A., and Hoff, R. M.: Evaluation of CHAMP radio occultation refractivity using data assimilation office analyses and radiosondes, Geophys. Res. Lett., 30, 1800, doi:10.1029/2003GL017637, 2003.

Poli, P., Healy, S. B. and Dee, D. P.: Assimilation of Global Positioning System radio occultation data in the ECMWF ERAInterim reanalysis, Q. J. Roy. Meteor. Soc., 136, 1972-1990, doi:10.1002/qj.722, 2010.

Rennie, M. P.: The impact of GPS radio occultation assimilation at the Met Office, Q. J. Roy. Meteorol. Soc., 136, 116-131, doi:10.1002/qj.521, 2010.

Rocken, C., Anthes, R., Mxner, M., Hunt, D., Sokolovskiy, S., Ware, R., Gorbunov, M., Schreiner, W., Feng, D., Herman, B., Kuo, Y.-H., and Zou, X.: Analysis and validation of GPS/MET data in the neutral atmosphere, J. Geophys. Res., 102, 2984929866, doi:10.1029/97JD02400, 1997.

Scherllin-Pirscher, B., Steiner, A. K., Kirchengast, G., Kuo, Y.-H., and Foelsche, U.: Empirical analysis and modeling of errors of atmospheric profiles from GPS radio occultation, Atmos. Meas. Tech., 4, 1875-1890, doi:10.5194/amt-4-1875-2011, 2011.

Schreiner, W. and Rocken, C.: Quality assessment of COSMIC/FORMOSAT-3 GPS radio occultation data derived from single- and double-difference atmospheric excess phase processing, GPS Solut, 14, 13-22, doi:10.1007/s10291009-0132-5, 2010.
Schreiner, W., Rocken, C., Sokolovskiy, S., Syndergaard, S., and Hunt, D.: Estimates of the precision of GPS radio occultations from the COSMIC/FORMOSAT-3 mission, Geophys. Res. Lett., 34, L04808, doi:10.1029/2006GL027557, 2007.

Schreiner, W., Sokolovskiy, S., Hunt, D., Rocken, C., and Kuo, Y.-H.: Analysis of GPS radio occultation data from the FORMOSAT-3/COSMIC and Metop/GRAS missions at CDAAC, Atmos. Meas. Tech., 4, 2255-2272, doi:10.5194/amt4-2255-2011, 2011.

Sokolovskiy, S. V.: Tracking tropospheric radio occultation signals from low Earth orbit, Radio Sci., 36, 483-498, 2001.

Sokolovskiy, S. V.: Effect of superrefraction on inversions of radio occultation signals in the lower troposphere, Radio Sci., 38, 1058, doi:10.1029/2002RS002728, 2003.

Sokolovskiy, S., Rocken, C., Schreiner, W., Hunt, D. C., and Johnson, J.: Postprocessing of L1 GPS radio occultation signals recorded in open-loop mode, Radio Sci., 44, RS2002, doi:10.1029/2008RS003907, 2009.

Spilker, J. J.: GPS signal structure and performance characteristics, Navigation, 25, 29-54, 1978.

Steiner, A. K., Lackner, B. C., Ladstädter, F., Scherllin-Pirscher, B., Foelsche, U., and Kirchengast, G.: GPS radio occultation for climate monitoring and change detection, Radio Sci., 46, RS0D24, doi:10.1029/2010RS004614, 2011.

Von Engeln, A., Healy, S., Marquardt, C., Andres, Y., and Sancho, F.: Validation of operational GRAS radio occultation data, Geophys. Res. Lett., 36, L17809, doi:10.1029/2009GL039968, 2009.

Vorob'ev, V. V. and Krasil'nikova, T. G.: Estimation of the accuracy of the atmospheric refractive index recovery from doppler shift measurements at frequencies used in the NAVSTAR system, Phys. Atmos. Ocean, 29, 602-609, 1994.

Wang, X.-Y., Sun, Y.-Q., Bai, W.-H., Du, Q.-F., Wang, D.-W., Wu, D., Yu, Q.-L., and Han, Y.: Simulation of number and distribution of COMPASS occultation events, Chinese J. of Geophysics, 56, 373-381, 2013.

Ware, R., Rocken, C., Solheim, F., Exner, M., Schreiner, W., Anthes, R., Feng, D., Herman, B., Gorbunov, M., Sokolovskiy, S., Hardy, K., Kuo, Y., Zou, X., Trenberth, K., Meehan, T., Melbourne, W., and Businger, S.: GPS sounding of the atmosphere from lower Earth orbit: preliminary results, B. Am. Meteorol. Soc., 77, 19-40, 1996.

Wickert, J., Reigber, C., Beyerle, G., Konig, R., Marquardt, C., Schmidt, T., Grunwaldt, L., Galas, R., Meehan, T. K., Melbourne, W. G., and Hocke, K.: Atmosphere sounding by GPS radio occultation: First results from CHAMP, Geophys. Res. Lett., 28, 3263-3266, 2001.

Yang, J., Zhang, P., Lu, N.-M., Yang, Z.-D., Shi, J.-M., and Dong, C.-H.: Improvements on global meteorological observations from the current Fengyun 3 satellites and beyond, Int. J. Digital Earth, 5, 251-265, 2012.

Yue, X., Schreiner, W. S., Lin, Y.-C., Rocken, C., Kuo, Y. -H., and Zhao B.: Data assimilation retrieval of electron density profiles from radio occultation measurements, J. Geophys. Res., 116, A03317, doi:10.1029/2010JA015980, 2011.

Zus, F., Beyerle, G., Heise, S., Schmidt, T., Wickert, J., and Marquardt, C.: Validation of refractivity profiles derived from GRAS raw-sampling data, Atmos. Meas. Tech., 4, 1541-1550, doi:10.5194/amt-4-1541-2011, 2011. 